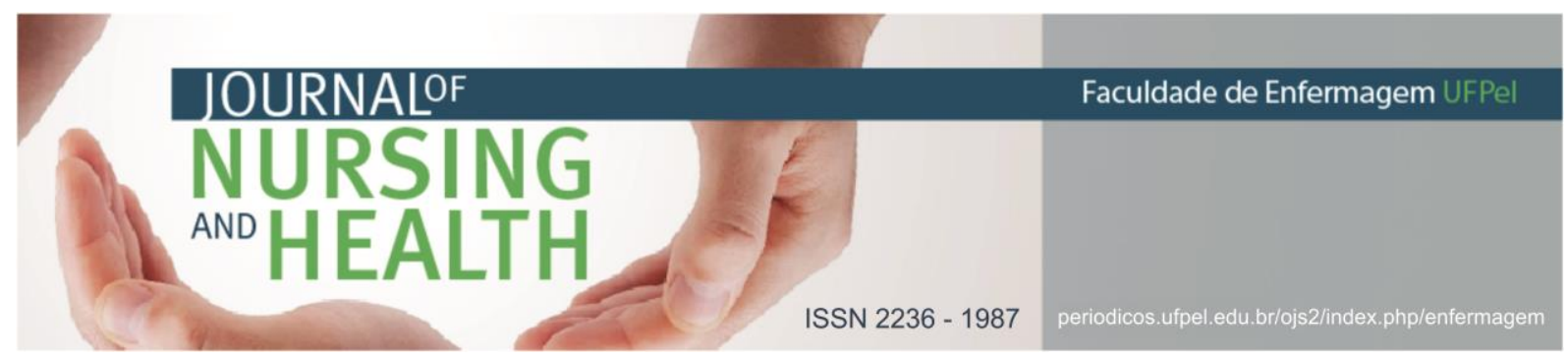

ARTIGO ORIGINAL

\title{
Situações de vida relacionadas ao aparecimento das vozes: com a palavra os ouvidores de vozes
}

\section{Life situations related to the appearance of voices: with the word the voice hearers}

\author{
Situaciones de vida relacionada al aparecimiento de voces: con la palabra los oidores \\ de voces
}

Kantorski, Luciane Prado¹; Cardano, Mario²; Couto, Maria Laura de Oliveira ${ }^{3}$; Silva, Marta Solange Streicher Janelli da ${ }^{4}$; Santos, Cátia Gentile dos $^{5}$

Como citar este artigo: Kantorski LP, Cardano M, Couto MLO, Silva LSSJ, Santos CG. Situações de vida relacionadas ao aparecimento das vozes: com a palavra os ouvidores de vozes. J. nurs. health. 2018;8(n.esp.):e188416

\section{RESUMO}

Objetivo: identificar na história de vida de ouvidores de vozes as situações relacionadas à origem das vozes. Método: os dados consistem em 21 entrevistas feitas com pessoas que participavam de grupos de Ouvidores de Vozes na localidade de Settimo Torinese (Itália) e imediações. Os dados foram coletados em 2015. Resultados: as entrevistas foram organizadas e analisadas relacionando a origem das vozes; a eventos de vida como sobrecarga no trabalho, perdas (separação, aborto, ruptura de laços amorosos) e a situações de adoecimento. Considerações finais: desenvolver estudos para conhecer as situações de vida relacionadas ao início da escuta das vozes pode contribuir para a abordagem e enfrentamento mais adequado a esta vivência.

Descritores: Saúde mental; Voz; Acontecimentos que mudam a vida.

\begin{abstract}
Objective: this study aims to identify in the life history of the voice hearers' situations related to the origin of voices. Method: the data consists of 21 interviews with people who participated in voice hearing groups in the town of Settimo Torinese - Italy and surroundings. Data were collected in 2015. Results: the interviews were organized and analyzed by relating the origin of voices to life events such as work overload, loss (separation, abortion, rupture of love bonds) and illness situations. Final Considerations: developing studies to know the life situations related to the beginning of listening to voices can contribute to the approach and coping more appropriate to this experience.
\end{abstract}

Descriptors: Mental health; Voice; Life change events.

1 Enfermeira. Doutora em Enfermagem. Universidade Federal de Pelotas (UFPEL). E-mail: kantorski@uol.com.br http://orcid.org/0000-0001-9726-3162

2 Professor Ordinario Dipartimento di Culture, Politica e Società- Università degli Studi di Torino. E-mail: mario.cardano@unito.it https://orcid.org/0000-0003-0268-3020

3 Psicóloga. Universidade Federal de Pelotas (UFPEL). E-mail: marialauradeoliveiracouto@gmail.com http: / /orcid.org/0000-0002-5103-3000

4 Psicóloga. Mestre em Educação Física. Universidade Federal de Pelotas (UFPEL). E mail: martajanelli@hotmail.com http://orcid.org/0000000314790544

5 Enfermeira. Mestre em Enfermagem. Universidade Federal de Pelotas (UFPEL). E-mail: catia.gentiles@gmail.com http://orcid.org/0000000348036371 


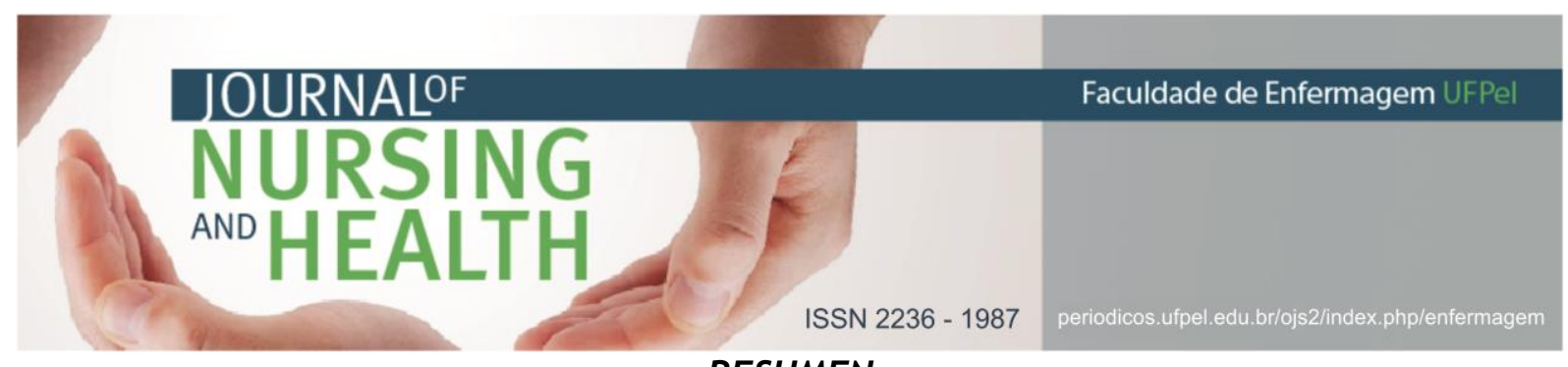

RESUMEN

Objetivo: identificar en la historia de vida de oyentes de voces las situaciones relacionadas al origen de las voces. Método: los datos consisten en 21 entrevistas con personas que formaban parte de grupos de Oidores de Voces en el lugar llamado Settimo Torinese - Italia y alrededores. Los datos fueron colectados en 2015. Resultados: las entrevistas fueron organizadas y analizadas de acuerdo con el origen de las voces a acontecimientos de vida, como sobrecarga en el trabajo, pérdidas (separación, aborto, rompimientos de enlaces amorosos) y situaciones de enfermedad. Conclusión: desarrollar estudios para conocer las situaciones de la vida relacionadas al comienzo de la escucha de las voces puede contribuir para al abordaje y enfrentamiento más adecuado a esta vivencia.

Descriptores: Salud mental; Voz; Acontecimientos que cambian la vida.

\section{INTRODUÇÃO}

O Movimento de Ouvidores de Vozes está entre os grupos de mais rápido crescimento no mundo. Portanto, para divulgar e promover a discussão acerca da audição de vozes, foi criada "uma organização formal que oferece suporte administrativo e coordena a ampla variedade de iniciativas em diferentes países, chamada de INTERVOICE (The International Network for Training, Education and Research into Hearing Voices)". 1:558 Além disso, existem redes nacionais de ouvidores de vozes em 26 países, as quais recebem apoio da Intervoice, sendo que esse atua como um órgão de coordenação internacional e é dirigido por um conselho constituído por pessoas que ouvem vozes e por profissionais especializados. ${ }^{1} \mathrm{O}$ site da INTERVOICE foi criado em 2007, com a proposta de iniciar "uma comunidade online interativa, [...] facilitando a troca de experiências na busca por formas de superação das dificuldades enfrentadas pelas pessoas que ouvem vozes". 1:561

Nesse site, muitos ouvidores compartilham suas experiências, desde estratégias para lidar com as vozes, dificuldades diárias, até suas histórias de vida, como quando começaram a ouvir vozes pela primeira vez. 0 início da audição de vozes "costuma ser inesquecível, e tem sido descrito como assustador, confuso, espiritual e, às vezes, até mesmo esclarecedor". 1:4 Essa afirmação é corroborada pelo estudo de Cottam ${ }^{2}$, que ao entrevistar 49 ouvidores de vozes, obteve relatos de eventos como a perda de um parente próximo, e situações de grandes repreensões na infância, como eliciadoras das vozes.

Assim, as vozes, algumas vezes, são consideradas como a manifestação de problemas emocionais que se apresentam de forma metafórica ou literal $^{3}$ podendo, consequentemente, desaparecer à medida que esses problemas forem resolvidos ou elaborados. ${ }^{4}$ Por esse motivo, é preciso prestar atenção às características das vozes, como, 'por exemplo, a sua idade, se esta é de uma criança, de um jovem ou de um idoso, pois ela pode representar a idade do ouvidor quando vivenciou o trauma. ${ }^{5}$ Esses dados se apresentam de forma metafórica como uma forma de proteger o ouvidor de entrar em contato direto com questões dolorosas e é por isso que se faz necessário respeitar o tempo de cada 


\section{ISSN 2236 - 1987}

ouvidor para que ele mesmo compreenda a natureza e o sentido das suas vozes. ${ }^{5}$

Outro aspecto interessante é que, ao mesmo tempo em que se torna amplamente difundida a ideia de que existe uma relação entre eventos traumáticos e audição de vozes ${ }^{6}$, não se tem encontrado diferenças nas taxas de eventos traumáticos vivenciados por ouvidores que fazem uso de serviço de saúde mental e dos que não fazem esse uso, ou seja, ao contrário do esperado, ambos apresentam altas taxas de trauma. ${ }^{7}$ Também ao contrário do que se imaginava, traumas vivenciados na infância e na adolescência não podem ser considerados preditores da necessidade de cuidado na fase adulta, como constatado pelo estudo de Daalman $^{8}$, ao comparar ouvidores de vozes que faziam uso de serviço de saúde mental, com os que não faziam. Esses estudos evidenciaram um dado muito significativo, de que existe um link causal entre trauma e audição de vozes, mas não entre trauma e necessidade de cuidado por causa da audição de vozes.

Nessa perspectiva, Romme e Escher $^{9}$ citam situações em que as vozes podem desempenhar um papel importante e reconfortante para o ouvidor, como é o caso de quando a voz pertence a alguém que faleceu e a mensagem que ela transmite é de que a pessoa está bem e sente-se satisfeita nos seus novos arredores. Em uma situação como essa, a voz pode ajudar - ouvidor a superar a perda e a vivenciar o luto, reafirmando, mais uma vez, a tendência de que a audição de vozes tem início frente a situações difíceis e traumáticas como um mecanismo de defesa do ouvidor, com a finalidade de ajudá-lo a lidar com sentimentos dolorosos. Portanto, investigar a história de vida do ouvidor a fim de identificar possíveis acontecimentos marcantes, tem se mostrado primordial no trabalho clínico. Frente ao exposto, o presente estudo teve como objetivo identificar, na história de vida de ouvidores de vozes, as situações relacionadas à origem das vozes.

\section{MATERIAIS E MÉTODOS}

Este artigo trata-se de um estudo de abordagem qualitativa, que integra a pesquisa intitulada "A constituição de práticas sociais desinstitucionalizantes no contexto das reformas psiquiátricas brasileira e italiana".

Os dados consistem em 21 entrevistas feitas com pessoas que ouvem vozes que os outros não escutam, e que participavam de Grupos de Ouvidores de Vozes na localidade de Settimo Torinese (Itália) e imediações. Os dados foram coletados em 2015.

As entrevistas foram gravadas, transcritas na íntegra, traduzidas do italiano para o português, organizadas, agrupadas e analisadas a partir de temáticas.

O referido projeto foi aprovado pelo Comitê de Ética da Faculdade de Medicina da universidade Federal de Pelotas, Parecer 750.144 de 31 de julho de 2014 obedecendo todos os procedimentos éticos previstos na legislação vigente. 


\section{IOURNALOF \\ NURSING \\ AND \\ RESULTADOS}

Neste espaço apresenta-se os dados, ou seja, as falas dos Ouvidores de Vozes obtidas nas entrevistas e organizadas em três temáticas em que os entrevistados relacionam o início das vozes a situações de trabalho, de perdas e de adoecimento.

\section{Trabalho}

O entrevistado 1 traz em seu relato a situação de desaparecimento da mãe que a deixou em choque e a levou a sair do emprego que tinha numa empresa de automóveis. Depois de dois anos desempregada, começou a trabalhar em outra empresa onde surgiram problemas. A saída de uma colega de trabalho levou ao excesso de trabalho, o que não fez bem para ela e então ela começou a usar medicamentos.

Em poucas palavras, em vez de contratar uma pessoa para a licença maternidade da minha colega, não contrataram ninguém [...] e eu fui forçada a fazer de 12 a 14 horas por dia [...] não conseguia mais coordenar bem o trabalho com a vida social [...] então começaram a dizer que eu não era confiável e eu deixei o emprego [...]. Depois me vi numa situação de ter que deixar a minha cidade porque não tinha trabalho [...]. Toda a paranoia imaginável começou a se manifestar. (E1)

O entrevistado 2 morava em um edifício onde o vizinho do apartamento de cima fazia festas até a madrugada. Teve dificuldades com esse fato e não
ISSN $2236-1987$

conseguia dormir, acabando por perder o emprego. Esse fato levou-o a brigar com o vizinho.

Fiquei hospitalizado quatro dias, $e$ as vozes continuaram a me perseguir e me criticando [...] me criticando, falando de forma vulgar. Por que para mim? Por que para mim? Me perseguiam em todos os lugares que eu ia. (E2)

A entrevistada 3 começou a trabalhar aos 21 anos sob grande estresse, pois o pai a pressionava para arranjar um emprego ao mesmo tempo em que ela desejava preparar-se para as provas finais do ensino médio.

Meu pai dizia: 'você deve trabalhar, porque depois não vai mais conseguir emprego'. (E3)

0 entrevistado 4 nasceu em Turim, tinha uma bela família, um bom relacionamento com os outros, fez o ensino médio e se tornou topógrafo. Começou a trabalhar até que veio a crise e não havia emprego, foi demitido.

Eu fiquei muito lento $e$ permanecia em casa, por saber do meu distúrbio psíquico fui bem acolhido [...]. Tive um distúrbio delirante estou me tratando e comecei a ouvir vozes. (E4)

0 entrevistado 5 relata estresse e fadiga e um contexto de instabilidade gerado pelas mudanças de emprego que causaram um estresse exagerado.

Primeiro trabalhei dois anos em um lugar, depois fui transferido para outro que eu nem me 
recordo direito onde era. Agora estou bem, gosto do que eu faço. (E5)

\section{Perdas}

A entrevistada 6 inicia contando como começou sua história de Ouvidora de Vozes.

A minha história começou quando caí em depressão, lentamente, sem perceber. Tive algum problema de um colapso depois de um luto. Morreu minha irmã que tinha um problema grave de saúde, que nos uniu no sofrimento. Eu sofri muito, tive que encarar a morte [...] então veio a paranoia, digamos assim [...] eu rezei tanto, orei tanto, invocando o Senhor, que me levou a ter crises místicas [...] depois, ouvi as vozes que me disseram: 'jogue-se fora da varanda'. É isso, e essa sou eu! (E6)

Segundo a entrevistada 7:

A minha história é de permanecer sozinha, porque sou órfã [...]. Certamente os primeiros dias eu ia frequentemente ao cemitério, levava flores, ia visitar meu pai todos os dias, no cemitério [...]. Dizem tantas vezes, quando você ouve vozes, isso significa que eles o chamam ou precisam de conforto [...] por isso eu fui muitas vezes na lápide do meu pai [...], mas agora eu não vou mais porque às vezes eu penso sobre isso, mas eu faço uma oração à noite e eu peço para que passe tudo, então consigo dormir. Não tenho mais medo, agora me digo que as vozes estão ali porque vivendo sozinha necessito também um certo encorajamento, a voz é como uma mãe que diz: te cuida, faz isso, faz aquilo. (E7)

0 entrevistado 8 relata uma situação de sua infância, de ter ficado órfão da mãe aos 5 anos, e crescer sem a presença da figura paterna, passando a viver com a avó e atribuindo as vozes a geração de conflito decorrente de sua história de vida quando conhece uma pessoa e tem a expectativa de formar uma família retomando a situação de perda dos pais:

Dali em diante começam as vozes, algumas vozes se iniciam relacionadas a esta situação [...] memórias que começam a fazer referência ao momento de crise e de conflito [...] as vozes antes de tudo, considerando o estresse emotivo ou físico da situação, eram uma válvula de escape. (E8)

O entrevistado 9, aos 21 anos, sofreu uma forte desilusão amorosa, pois foi abandonado pela noiva.

As vozes vieram após uma desilusão amorosa muito forte, fui abandonado pela minha noiva, quando já falávamos em nos casar. Logo após ouvi a voz dela, levando-me a fazer coisas bastante inconvenientes, como fugir do quartel para viajar pela Itália. (E9)

O entrevistado 10 informa o início das vozes a partir de um aborto de sua companheira. Relata que tinha um relacionamento conflitivo com a mãe e 
aos 17 anos e meio conheceu uma garota, que ela não era linda e tinha muitas qualidades. Então com 18 anos foi morar com ela contra a vontade dos pais. Ela engravidou e a mãe dele dizia que ele não deveria casar e que eles não deveriam ter o filho, sucedeu-se um aborto e a partir daí começaram os seus conflitos internos.

Eu ouço todas as vozes, ouço a voz do Papa, a voz do anjo, o diabo também estava lá. Senti quando Satanás assumiu as vozes verdadeira, e realmente fiquei assustado! É realmente ruim! (E10)

0 entrevistado 11 refere que os pais se separaram quando ele tinha apenas seis anos. Foi bastante conflitiva, envolvendo uma mãe alcoolista e um pai com diversas relações amorosas instáveis.

O período que morei com a minha mãe, que já era alcoolista, e a minha irmã, vivia um estado emocional difícil. Uma vez, a meia-noite, estávamos na rua e minha mãe perdeu as chaves da casa. Depois desse episódio tive que ir morar com o meu pai [...]. Passado um tempo, eu já com 11 anos, voltei a morar com a minha mãe, ainda alcoolista, porque foi difícil para mim tentar conviver com as tentativas de casamento do meu pai que não deram certo. (E11)

O entrevistado 12 menciona a separação dos pais e o impacto na sua vida.

Meus pais se separaram quando eu era pequeno. 0 meu pai era muito severo, não sabia manter a harmonia e a afetividade na casa. Minha primeira crise aconteceu após vários encontros com ele. Respeito às vozes porque elas são a minha consciência. É como uma autoridade falando comigo. (E12)

0 entrevistado 13 associa o aparecimento das vozes à ruptura do seu noivado.

Questões religiosas me levaram a romper o noivado. Logo após, comecei a ouvir vozes. Vozes que eram de Deus, de Maria. Sentia premonições sobre o futuro, já havia previsto dentro de mim o tsunami, o atentado à Berlusconi, a guerra no Iraque e que o Bush seria eleito. (E13)

\section{Situações de adoecimento}

O entrevistado 14 relata uma adolescência muito particular, o pai sofria de depressão e fazia acompanhamento, portanto não trabalhava e a mãe tinha que dar conta de tudo.

Aos 25 anos estava convencido de que era telepata, que conseguia entender os pensamentos dos interlocutores que estavam diante de $\operatorname{mim}[. .$.$] . Tive um$ colapso físico e psicológico. Fazia confidencias à enfermeira do serviço[...]. Repousava, mas toda noite ouvia as vozes. (E14)

A entrevistada 15 conta que aos 23 anos sofreu um acidente grave que causou distúrbio nervoso e psíquico, traumatismo craniano e invalidez. Durante seis anos ela ia de uma casa de tratamento para outra, não tinha 


\section{JOURNALOF \\ NURSING \\ ${ }^{\text {ANO }} \mathrm{HEALTH}$}

ISSN 2236 - 1987

0 entrevistado 18 relaciona o aparecimento das vozes com situações de bulling vivenciados na infância. Conta que, na escola, os colegas caçoavam dele porque era franzino e magrelo. Ele não aguentava mais o deboche, pois o chamavam de alcachofra.

'Alcachofra! Alcachofra!' Um dia no ônibus ouvi essas vozes. Olhei a minha volta e não tinha ninguém a gritar, essas vozes eram do ônibus. (E18)

A entrevistada 19 diz que frequentava $o$ terceiro ano para formação do magistério e que obtinha boas notas até que foi para exame, sendo reprovada. Segundo ela, foi reprovada por uma professora que não gostou do que escreveu, o que a motivou a parar de estudar. Ela, na época em que estudava, ficou muito fatigada considerando que quando estudava ficava incomodada com os objetos que a cercavam.

Assim, depois desta situação de ser reprovada na escola, começaram as vozes e então eu fiquei depressiva. (E19)

0 entrevistado 20 relata que aos 17 anos começou a ouvir vozes após sua primeira experiência com 0 uso de drogas (maconha).

Então procurei um psicólogo que me disse que eu tinha duas personalidades, $e$ que esta personalidade tinha me levado a ouvir vozes. Depois, fui de férias a Roma e tive a impressão de ter visto uma luz no céu, uma luz estranha, tipo um extraterrestre. Depois de ver a luz, ouvi vozes 
que falavam: 'eu quero te proteger'. Uma voz muito protetiva, que parecia a voz de Deus. (E20)

A entrevistada 21 associa o aparecimento das vozes a uma situação de violência, abuso sexual.

Aos 21 anos encontrei um rapaz muito mais velho (29-30 anos) que me tratou muito mal [...] sofri abuso e esta situação durou cinco meses. Porém na minha cabeça, permaneceu o choque, porque fui violentada. Isto permaneceu na minha cabeça como um disco quebrado. Por dois anos eu não saía de casa. Tive uma crise psicótica esquizofrênica. (E21)

\section{DISCUSSÃO}

\section{Trabalho}

A relação entre trabalho e o surgimento das vozes se deu de diferentes formas. Ocorreram situações de excesso de trabalho, o que gerou instabilidade emocional e familiar; conflitos do cotidiano que levaram à perda do emprego; situação de pressão familiar para o ingresso no mercado de trabalho paralelo ao desejo de dedicar-se aos estudos; perda de emprego como resultado da crise econômica do local onde o sujeito residia; e instabilidade emocional gerada pelas mudanças frequentes de local de trabalho.

Uma das mudanças que mais afetam as pessoas na atualidade, são as relacionadas às atividades laborais. Isso se dá, principalmente, em função da necessidade de estar inserido e
ISSN 2236 - 1987

produtivo no mercado de trabalho, que se apresenta cada vez mais exigente e competitivo. ${ }^{10}$ Dentre as situações que geram desgaste emocional pode-se citar funções administrativas, responsabilidade dos serviços prestados, excesso de esforço físico, falta de material e pessoal, questões salariais, conflitos e competitividade entre os profissionais, entre outros. ${ }^{15}$ Essas situações, de sobrecarga no trabalho, geram um complexo estado físico e psíquico de estresse ocupacional e familiar. ${ }^{11}$

\section{Perdas}

Situações de perda e processos de luto, podem dar início a audição de vozes, como constatado a partir da análise das entrevistas. A morte de familiares, como pais e irmãos se mostrou bastante significativa, bem como o rompimento de relações amorosas, situação de aborto, separação dos pais, mudança de cidade, acarretando no distanciamento dos amigos, das atividades de lazer cotidianas e outras referências.

O processo de luto é vivenciado de forma particular para cada indivíduo e pode ser influenciado pelas características do sistema familiar, o qual pode vir a potencializar ou prejudicar esse processo, "dependendo do nível de abertura para comunicação e o nível de coesão entre os membros da família". 12:1120

Essas diferentes formas de vivenciar o processo de luto ficam evidentes nas entrevistas, principalmente no que se refere a perda de pais e irmãos. A experiência dessa perda para uma das ouvidoras, acarretou em uma relação positiva com 


\section{JOURNALOF \\ NURSING \\ AND HEALTH}

ISSN 2236 - 1987

as vozes, de companhia e afetividade, enquanto que para outro ouvidor, que perdeu a mãe, resultou na audição de vozes negativas e ego-distônicas, visto que as mesmas ordenavam que ele se jogasse da sacada, dando fim a sua vida.

Portanto, pode haver características do sistema familiar a afetar o processo de luto, assim como cada indivíduo difere na expressão do seu próprio luto ${ }^{2}$. A vivência do luto pode ser potencializada ou prejudicada de acordo com a abertura para a comunicação e o nível de coesão entre os membros da família ${ }^{5}$, por isso, um bom funcionamento familiar durante a fase de prestação de cuidados ao doente e principalmente no luto é importante para o bem-estar psicológico dos seus membros.

Sabe-se que as vozes podem variar, tanto em termos de conteúdo, podendo ser de comando, de comentário, de insulto ou afirmação, bem como frequência, duração, localização, número, entre outros. Além disso, as vozes costumam ser vivenciadas como identidades já conhecidas $^{13}$, como é o caso do ouvidor que foi abandonado pela noiva e passou a ouvir a voz dela. Os ouvidores muitas vezes se relacionam com as vozes da mesma forma como se relacionam com pessoas do seu meio social, podendo atribuí-las "a um poder superior, espíritos, membros da família falecidos ou mensagens geradas por rádio, televisão ou mídias sociais". ${ }^{13: 2}$

O processo de separação dos pais, vivenciado de forma conflituosa por alguns ouvidores, contribuiu significativamente para o início da audição de vozes, visto que, as responsabilidades parentais quando não alcançadas, facilitam o surgimento de demandas somáticas e emocionais, necessárias para o alcance da maturação física e psíquica. ${ }^{14}$

\section{Situações de adoecimento}

Vivências do cotidiano podem promover adoecimento, facilitando o surgimento das vozes. Dentre as experiências partilhadas pelos entrevistados, é possível identificar a ocorrência de doença na família como geradora de sobrecarga emocional, assim como situações de traumas físicos, acidentes, coma, conflitos escolares, abuso de substância e abuso sexual.

Ao identificar a origem das vozes, e estabelecer uma relação com as mesmas, torna-se possível ressignificar a experiência e normalizá-la através de uma compreensão mais profunda acerca do trauma vivenciado. ${ }^{15}$ Logo, "normalizar a experiência significa redimensionar 0 medo"15:84-5, permitindo reflexões acerca do trauma, seus sintomas, conteúdo e identidade das vozes, retirando de si, a culpa diante das situações experimentadas ao longo da sua trajetória, e assim, aprendendo a conviver com estas.

Quem ouve as vozes vive aquele momento de ouvir como uma certeza, então o problema não é acreditar ou não acreditar em ter ouvido uma voz, mas sim refletir sobre suas próprias certezas $e$ necessidades. ${ }^{15: 55}$

A negligência, diante de eventos traumáticos na infância e 


\section{NURSING \\ AND}

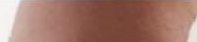

ISSN 2236 - 1987

adolescência,

representa

a

possibilidade do sujeito tornar-se mais vulnerável psiquicamente diante de novos eventos, ou seja, de ter sua capacidade de resiliência diminuída. ${ }^{16}$

\section{CONSIDERAÇÕES FINAIS}

Através das entrevistas com os ouvidores, foi possivel identificar diferentes circunstâncias traumáticas que deram início a audição de vozes. De forma condizente com a literatura, também ficou evidente que a maneira como o ouvidor se relaciona com as vozes, diz muito de como ele lida com a experiência traumática vivenciada, ou seja, denuncia se essa experiência está bem elaborada ou não.

Outro aspecto que também ficou evidente, foi a importância de se investigar as características das vozes, se elas são positivas ou negativas, se agregam à vida do ouvidor no sentido de ajudá-lo a lidar com situações cotidianas e, principalmente, investigar de que forma as vozes estão relacionadas com a situação traumática vivenciada. Portanto, a importância da investigação acerca da história de vida do ouvidor se mostrou primordial para ressignificar a experiência de ouvir vozes e facilitar uma relação positiva com as mesmas.

\section{REFERÊNCIAS}

1 Barros OC, Serpa Júnior O D de. Ouvir vozes: um estudo sobre a troca de experiências em ambiente virtual. Interface comun saúde educ [Internet]. 2014 [acesso em 2018 ago 11];18(50):557-69. Disponível em: http://www.scielo.br/pdf/icse/v18n5 0/1807-5762-icse-1807-

576220130680.pdf

2 Cottam S, Paul SN, Doughty OJ, Carpenter L, Al-Mousawi A, Karvounis S et al. Does religious belief enable positive interpretation of auditory hallucinations? A comparison of religious voice hearers with and without psychosis. Cogn Neuropsychiatry [Internet]. 2011 [cited 2018 Aug 11]:16(5):403-21. Available from:

https: / /www.tandfonline.com/doi/ful l/10.1080/13546805.2010.548543

3 McCarthy-Jones S, Longden E. The voices others cannot hear. The psychologist [Internet]. 2013[cited 2018 Aug 11]:26(8):570-74. Available from:

https: / / thepsychologist.bps.org.uk/vo lume-26/edition-8/voices-others-

cannot-hear

4 Escher S, Romme $M$, Buiks $A$. Smalltalk: Voice hearing in children. Open Mind; 1998:12-4.

5 Romme $M$, Escher S, Dillon J, Corstens D, Morris M. Living with Voices: 50 stories of recovery. Monmouth: PCCS Books; 2009.

6 Varese $P$, Smeets F, Drukker $M$, Lieverse R, Lataster T, Viechtbauer W et al. Childhood adversities increase the risk of psychosis: a meta-analysis of patient-control, prospective- and cross-sectional cohort studies. Schizophr bull [Internet]. 2012[cited 2018 Aug 11]:38(4):661-71. Available from:

https://www.ncbi.nlm.nih.gov/pmc/a rticles/PMC3406538/

7 Andrew EM, Gray NS, Snowden RJ. The relationship between trauma and beliefs about hearing voices: a study of 


\section{JOURNALOF \\ NURSING \\ AND 느는}

ISSN 2236 - 198

psychiatric and non-psychiatric voice hearers. Psychological medicine [Internet]. 2008[cited 2018 Aug 11]:38(10):1409-17. Available from: https://www.cambridge.org/core/jou rnals/psychological-

medicine/article/relationship-

between-trauma-and-beliefs-abouthearing-voices-a-study-of-psychiatricand-nonpsychiatric-voicehearers/F216516F6183F6416087A9419 06839E4

8 Daalman K, Sommer IEC, Derks EM, Peters ER. Cognitive biases and auditory verbal hallucinations in healthy and clinical individuals. Psychological medicine[Internet]. 2013[cited 2018 Aug 11]:43(11):233947. Available from: https://www.cambridge.org/core/jou rnals/psychologicalmedicine/article/cognitive-biasesand-auditory-verbal-hallucinations-inhealthy-and-clinicalindividuals/E5779029A4C6F7D791CA8B 7FE374D988

9 Romme M, Escher S. Making sense of voices: a guide for mental health professional working with voicehearers. London: Mind Publications; 2000.

10 Decezaro A, Frizon G, Silva OM, Toniollo CL, Busnello GF, Ascari RA. O estresse dos enfermeiros que atuam na unidade de terapia intensiva: uma revisão de literatura. Revista UNINGÁ review [Internet]. 2014 jul/set[acesso em 2018 ago 11]:19(2):29-32. Disponível em: https: / /www.mastereditora.com.br/p eriodico/20140801_093235.pdf

11 Sadir MA, Lipp MN. Influência do treino de controle do estresse nas relações interpessoais no trabalho. Mundo saúde [Internet]. 2013[acesso em 2018 ago 11];37(2):131-40. Disponível em: https: / / www.saocamilosp.br/pdf/mundo_saude/102/1.pdf

12 Delalibera $M$, Presa J, Coelho A, Barbosa A, Franco MHP. A dinâmica familiar no processo de luto: revisão sistemática da literatura. Ciênc saúde colet [Internet]. 2015[acesso em 2018 ago 11];20(4):1119-34. Disponível em: http://www.scielo.br/pdf/csc/v20n4/ pt_1413-8123-csc-20-04-01119.pdf

13 Rosen C, Jones N, Chase KA, Grossman LS, Gin H, Sharma RP. Self, voices and embodiment: a phenomenological analysis. J schizophr res [Internet]. 2015[cited 2018 Aug 11]; 2(1): 1008. Available from: https: / /www.ncbi.nlm.nih.gov/pmc/a rticles/PMC4834921/

14 Nazareth ER. Família e divórcio. In: Cerveny CMO, organizador. Família e...: comunicação, divórcio, mudança, resiliência, deficiência, lei, bioética, doença, religião e drogadição. São Paulo: Casa do Psicólogo; 2013.

15 Contini C. Ouvir vozes: manual de enfrentamento. Pelotas: Cópias Santa Cruz; 2017.

16 Dvir Y, Denietolis B, Frazier JA. Childhood Trauma and Psychosis. Child adolesc psychiatric clin $n$ am [Internet]. 2013[cited 2018 Aug 11];22(4): 629-41. Available from: https://www.sciencedirect.com/scien ce/article/pii/S1056499313000291?via \%3Dihu

Data de publicação: 19/09/2018 